\title{
Assessment of Radiological Contamination of Soils Due to Shipbreaking Using HPGe Digital Gamma-Ray Spectrometry System
}

\author{
Mohammad Kamal Hossain ${ }^{1}$, Syed Mohammod Hossain², Rezaul Azim¹, AKM Moinul Haque Meaze ${ }^{\text {* }}$ \\ ${ }^{1}$ Department of Physics, University of Chittagong, Chittagong, Bangladesh; ${ }^{2}$ Institute of Nuclear Science and Technology (INST), \\ Atomic Energy Research Establishment (AERE), Savar, Dhaka, Bangladesh; *Corresponding Author. \\ Email: *mhqmeaze@yahoo.com
}

Received December $6^{\text {th }}, 2009$; revised February $1^{\text {st }}, 2010$; accepted February $3^{\text {rd }}, 2010$.

\begin{abstract}
A systematic study of the distribution of the Naturally Occurring Radioactive Materials as well as the anthropogenic radionuclide in the working environment of the Shipbreaking yards of Sitakunda, Chittagong, Bangladesh, has been carried out with an objective of establishing reliable base line data on the radiation level and hence to measure the radiation dose expose to the workers and to the inhabitants of the studied area. Fifteen Soil samples have been collected from five different Shipbreaking yards. Three sampling spots in each yard have been selected for having representative samples for the assessment of radioactivity releasing from ${ }^{226} \mathrm{Ra}\left({ }^{238} \mathrm{U}\right),{ }^{232} \mathrm{Th}$ and their daughters and ${ }^{40} \mathrm{~K}$ using the Digital Gamma-ray Spectrometry system coupled with a High Purity Germanium (HPGe; Canberra, 40\% relative efficiency, $1.8 \mathrm{keV}$ resolution at $1332 \mathrm{keV}$ of ${ }^{60} \mathrm{Co}$ ) detector and PC based Multichannel Analyzer (MCA, upto 16k channel). The software Genie 2000 (Canberra) and Hypermet PC have been used for data acquisition and gamma peak analysis, respectively. Each of fifteen soils ( 200g) and two standards (IAEA-Soil-6 and 800Bq liquid ${ }^{226}$ Ra sprayed in $\mathrm{Al}_{2} \mathrm{O}_{3}$ ) were counted in cylindrical plastic pot using gamma spectrometry system for 20000 sec for the determination of activity concentrations of the radionuclides. The samples and standards were kept in air tied condition at least for 4 weeks before gamma counting to attain the radioactive equilibrium between daughters and parents of ${ }^{226} R a\left({ }^{238} U\right)$ and ${ }^{232}$ Th decay series. The $\mathrm{Al}_{2} \mathrm{O}_{3}$ based ${ }^{226} \mathrm{Ra}$ standard was used for the construction of efficiency curve covering the wide gamma energy range. The IAEA-Soil-6 was used for quality control $(Q C)$ of the analysis. The homogeneity test and density corrections of $\mathrm{Al}_{2} \mathrm{O}_{3}$ based ${ }^{226} \mathrm{Ra}$ standard were performed and implemented for the analysis. The results of activity concentrations have been used to assess the radium equivalent activities $\left(R a_{e q}\right)$ and the representative level index $\left(I_{\gamma r}\right)$ values in the experimental soil samples. The results have been compared with other global radioactivity measurements and evaluations.
\end{abstract}

Keywords: Shipbreaking Yards, HPGe Detector, Radionuclides, Activity Concentrations, Dose Rates, Radium Equivalent Activity, Representative Level Index

\section{Introduction}

The world is naturally radioactive and hence human being on earth evolved in a radioactive environment. About $90 \%$ of the human radiation exposure arises from natural sources such as terrestrial radiation, cosmic radiation, and radon gas. Natural radionuclides of concern are thorium $\left({ }^{232} \mathrm{Th}\right)$ and uranium $\left({ }^{238} \mathrm{U}\right)$ with their radioactive decay chains and potassium $\left({ }^{40} \mathrm{~K}\right)$. Emanation of radon gas $\left({ }^{222} \mathrm{Rn}\right.$ and $\left.{ }^{220} \mathrm{Rn}\right)$ into air occurs as a product of uranium $\left({ }^{238} \mathrm{U}\right)$ and thorium $\left({ }^{232} \mathrm{Th}\right)$ decay chain respectively. Like all other materials soil can also be the source of radon gas [1].
Assessment of any release of radioactivity to the environment is important for the protection of public health; especially if the released radioactivity is a matter of direct population exposure and can enter into the food chain [2], which is a matter of indirect exposure. In the case of the workers of the shipbreaking yards and the peoples living round the yards, peoples are subjected to both direct and indirect radiation exposures.

The whole activities of shipbreaking in Bangladesh are done in an unhygienic environment with the violation of the safety regulations. During the dismantling of the ships different chemicals, gases, oils, ballast water, etc., fall in the sea water which pollute the marine environ- 
ment. Also after dismantling of the ships the scraps carrying the poisonous materials like chemicals, gases, oils etc., radioactive materials, and heavy metals in its paints and electric equipments-pollute the soil and the surrounding environment where they are stored. As a result of these, today, shipbreaking becomes a threat to the environment and hence to human health.

Now from the point of view of natural risk, it is necessary to measure the environmental radiation level for the estimation of the exposures of natural radiation sources and to know the dose limit of public exposure. Therefore the main object of this study is to assess the environmental radioactive contamination in the working environment of the shipbreaking yards of Sitakunda, Chittagong, Bangladesh, through finding out the types and concentrations of the radionuclides in the soil of the yards. With the above considerations and with a view to ensure the significant contribution of the shipbreaking to the national economy of Bangladesh, fifteen (15) soil samples have been collected from 5 different shipbreaking yards of Sitakunda, Chittagong, with 3 samples from each. The samples were analyzed by the HPGe detector coupled with computer based digital gamma spectrometry system and sophisticated data acquisition and gamma peak analysis software in the NAA laboratory of the Institute of Nuclear Science \& Technology (INST), Atomic Energy Research Establishment (AERE), Savar, Dhaka, Bangladesh.

\section{Materials and Methods}

\subsection{Sample Collection and Processes}

Most of the shipbreaking yards of Bangladesh are situated in different locations (Fultola, Baro Awlia, Kadam rasul, Jahanabad, Kumira, Kattoli, etc.) under Sitakunda thana of Chittagong District. That is why for the present research five different shipbreaking yards of Sitakunda, Chittagong, Bangladesh are selected as sites for sample collection.

After cleaning the surface, soil was collected from 0-30 cm depth by auguring. Three soil samples were collected in cleaned polyethylene bag from each of five shipbreaking yards. The samples were marked separately by giving the identification (ID) number carefully. The name and addresses of the shipyards with soils identity are quoted in Table 1. It is noted that in the Table 1 the letters A, B, C are given for three different locations of each yard.

The collected soil samples were taken in a pre-cleaned pyrex beaker and then allowed to dry in the oven at $70^{\circ} \mathrm{C}$ until having constant weight. The dried soil samples were taken then powdered by the use of an agate mortar. Fifteen (15) cleaned cylindrical plastic pots having the same geometry were filled with about 200g dried powered samples and kept in air tied condition. All the air tied pots were remained undisturb at least for 4 weeks before counting to attain parents-daughter equilibrium in the ${ }^{238} \mathrm{U}$ and ${ }^{232} \mathrm{Th}$ decay series. For example, the ${ }^{222} \mathrm{Rn}$ from ${ }^{238} \mathrm{U}$ decay series can easily be escaped by diffusion from the samples during preparation. As the half-life of ${ }^{222} \mathrm{Rn}$ is 3.84 days, once the ${ }^{222} \mathrm{Rn}$ escaped from the sample it is needed at least 7 half-lives to attain equilibrium.

For measuring the natural radioactivity two standards were used. One was IAEA Soil-6 and the other was ${ }^{226} \mathrm{Ra}$ (liquid) sprayed into $\mathrm{Al}_{2} \mathrm{O}_{3}$. The $\mathrm{Al}_{2} \mathrm{O}_{3}$ standard was prepared in the INST laboratory. For the preparation of $\mathrm{Al}_{2} \mathrm{O}_{3}$ standard ${ }^{226} \mathrm{Ra}$ liquid having an initial activity $800 \mathrm{~Bq}$ was sprayed into the $\mathrm{Al}_{2} \mathrm{O}_{3}$ powder. The liquid was sprayed carefully and mixed homogeneously. The homogeneity test of $\mathrm{Al}_{2} \mathrm{O}_{3}$ standard was performed by splitting it into 6 equal folds and measured them in the sample geometry of HPGe_detector. Both the standards were also packed in the plastic pots having the same geometry and height as that of samples. The IAEA-Soil-6 and samples have almost the same packing density, whereas has lower packing density. The density corrections were performed and taken into account for the calculation.

The accuracy of any experimental analysis depends mainly on the performance of the detection system. On the other, the performance of any detection system depends on some parameters of the experimental set up. Therefore in the present experiment some useful parameters of the HPGe detector were determined to ensure the accuracy of the analysis. We have performed energy calibration, resolution, counting efficiencies of the HPGe detector, Quality Control Chart (QC) for Instrumental Quality, etc. and details of these parameters analyses techniques are almost same as on Reference [3].

Table 1. Name and addresses of investigated shipyards with soils identity

\begin{tabular}{lc}
\hline \multicolumn{1}{c}{ Name and Address of the yard } & Sample ID \\
\hline Rising Steel Ltd. & S-1A \\
(Ship Breaking Unit) & S-1B \\
Fultola, Baro Aulia, Sitakunda, Chittagong. & S-1C \\
Ziri Subader Steel & \\
Re-Rolling Mills & S-2A \\
(Ship Breaking Unit), & S-2B \\
BaroAulia, Sitakunda, Chittagong. & S-2C \\
Muhib \& Sakib Steel Industries & \\
(Ship Breaking Unit), & S-3A \\
Kadam Rasul, Vatiary, Sitakunda, Chittagong. & S-3B \\
M/S. Sultana Ship Breaking & S-3C \\
Yard, & S-4A \\
Kadam Rasul, Vatiary, Sitakunda, Chittagong. & S-4B \\
M/S. Six Star Corporation (Ship Breaking Yard), & S-4C \\
Jahanabad, Sitakunda, Chittagong. & S-5A \\
\hline
\end{tabular}




\subsection{Counting of the Samples and Standards}

In counting system a count was taken for 20000 seconds for each of the samples and standards of interest. The standards for homogeneity testing were counted for 7200 second each. The spectra in all cases were saved in the PC. A background count for the time 20000 seconds was taken to get the background contribution in the samples and standards.

\subsection{Analysis of the Spectra}

The spectra collected for the samples and standards were analyzed in two ways: manually and by the use of analyzing software Hypermet PC version -5.12. The area under the peak of a certain gamma ray energy spectrum represents the number of counts collected only for that gamma ray energy. For the manual evaluation of the peak area, equal numbers of channels were taken on each side of the peak. Hypermet PC version -5.12 gave the area automatically. Both the peak analysis methods yielded almost consistent peak area for the interested radionuclide.

\subsection{Interference Correction}

The interference corrections have been performed in some cases. ${ }^{232} \mathrm{Th}$ and ${ }^{226} \mathrm{Ra}$ have gamma peaks at 240.98 $\mathrm{keV}$ and at $241.98 \mathrm{keV}$ energies, respectively. It is difficult for any detector to show the peaks separately, so there is always a spectral interference between them. Hence to calculate the correct peak area from the interfered peaks, interference correction was made in the current experiment.

The conversion of the measured to the correct peak area $[\mathrm{Np}]$ is performed as:

$$
\left[N_{p, a}\right]_{\text {Correct }}=\left[N_{p, a+b}\right]-\left[N_{p, r e f}\right] \frac{\left[I_{\gamma} \times \varepsilon_{P}\right]_{b}}{\left[I_{\gamma} \times \mathcal{E}_{P}\right]_{r e f}}
$$

where $I_{\gamma}$ is the gamma ray intensity, " $a$ " denotes the interfered peak, " $b$ " the interfering peak, "ref" is an undisturbed peak from the interfering radionuclide and " $\varepsilon$ " the efficiency.

\subsection{Density Corrections}

In the present work density correction was made to determine how the gamma rays are affected by the density and composition of the samples \& standards. For this, IAEA-Soil-6, $\mathrm{Al}_{2} \mathrm{O}_{3}$ standards and gamma emitting point sources of ${ }^{60} \mathrm{Co},{ }^{133} \mathrm{Ba},{ }^{137} \mathrm{Cs}$ and ${ }^{152} \mathrm{Eu}$ covering the low and high energies were used. The CPS ratio of various gamma energies emitting from point sources and passing through both the standards were determined and plotted as in Figure 1.

It is seen that at very low energy (80.99 $\mathrm{keV}$ ) the gamma-rays passing through the IAEA soil-6 standard is $10 \%$ affected compared to that through the $\mathrm{Al}_{2} \mathrm{O}_{3}$ standard. But at high energies there was no effect at all; the CPS ratio is around 1 .

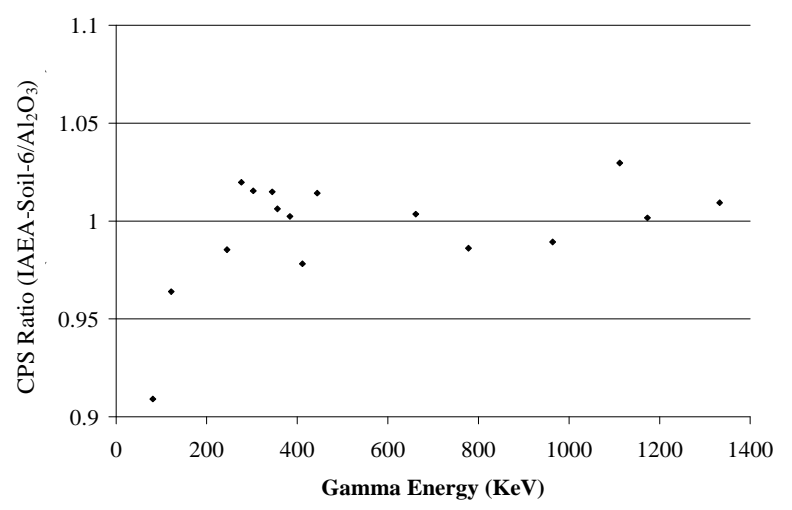

Figure 1. The effect of packing density and composition of the sample on gamma ray energies

\subsection{Homogeneity Testing}

The homogeneity of the $\mathrm{Al}_{2} \mathrm{O}_{3}\left({ }^{226} \mathrm{Ra}\right)$ standard was tested by measuring the specific count rate (CPS/g) for six folds for particular gamma energy. It was found that the CPS's were the same at $768.36 \mathrm{keV}$ of ${ }^{226} \mathrm{Ra}$. This confirmed the homogeneity of the $\mathrm{Al}_{2} \mathrm{O}_{3}$ standard (Figure 2).

\section{Calculations of Activity Concentrations, Dose Rate, Radium Equivalent Activity and Representative Index}

Soil samples were collected to determine the activity concentrations, their corresponding dose rates and other radioactivity indices e.g., radium equivalent activity and representative level index, etc. The activity concentrations were measured from the following relation:

$$
A=\frac{C P S \times 1000}{\varepsilon(a b s) \times I_{\gamma}(a b s) \times W}
$$

where $A$ is the activity in Bq. $\mathrm{kg}^{-1}$, CPS is the net counts per second of the experimental sample, $W$ is the weight of the sample in gm, $\varepsilon(a b s)$ is the absolute gamma peak detection efficiency, $I_{\gamma}(a b s)$ is the absolute gamma intensity of the corresponding gamma ray energy.

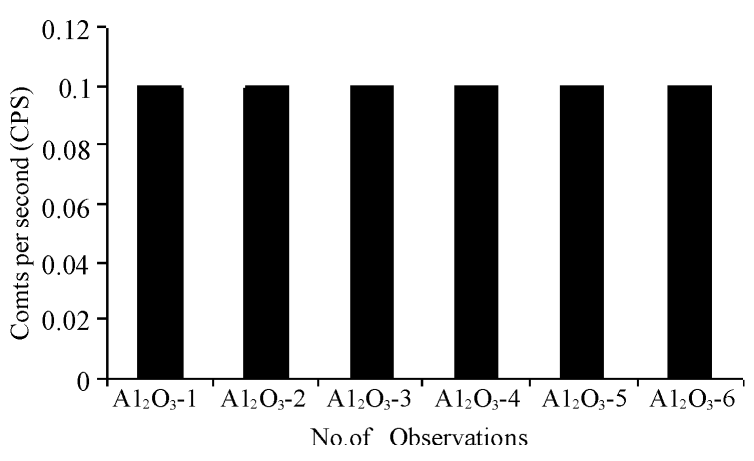

Figure 2. Homogeneity testing of the $\mathrm{Al}_{2} \mathrm{O}_{3}$ standard 
To determine the activity concentrations of ${ }^{226} \mathrm{Ra}$ $\left({ }^{238} \mathrm{U}\right)$, the $\gamma$-ray lines 295.21, $351.92 \mathrm{keV}\left({ }^{214} \mathrm{~Pb}\right) ; 609.31$ and $1120.29 \mathrm{keV}\left({ }^{214} \mathrm{Bi}\right)$ were used. To determine the activity concentrations of ${ }^{232} \mathrm{Th}$, the $\gamma$-ray lines 911.07 , $969.11 \mathrm{keV}\left({ }^{228} \mathrm{Ac}\right) ; 238.63 \mathrm{keV}\left({ }^{212} \mathrm{~Pb}\right) ; 583,2614.66$ $\mathrm{keV}\left({ }^{208} \mathrm{Tl}\right)$ were used.

The dose rate in the studied area was calculated from the formula reported in Reference [2] as:

$$
\begin{aligned}
D= & (0.0427) C_{R a-226}+0.0662 C_{T h-232}+ \\
& \left.0.00432 C_{K-40}\right) \times\left(10^{-8} \mathrm{~Gy} \cdot \mathrm{h}^{-1}\right)
\end{aligned}
$$

where, D-the dose rate (equivalent to the external dose rate), $C_{R a-226}, C_{T h-232}$ and $C_{K-40}$ are the average activity concentrations of ${ }^{226} \mathrm{Ra}$, ${ }^{232} \mathrm{Th}$ and ${ }^{40} \mathrm{~K}$ contents respectively in the experimental soil.

The internal dose rate is assumed to be 1.2 times higher than the external dose rate [4]

$$
D_{\text {internal }}=D_{\text {external }} \times 1.2\left(\mathrm{nGy} \cdot \mathrm{h}^{-1}\right)
$$

The transformation of activity into the radium equivalent activity, $R a_{e q}$, was performed according to Reference [5] as:

$$
R a_{e q}=C_{R a}+(10 / 7) C_{T h}+(10 / 130) C_{K}
$$

Another radiation index, named representative level index can be defined as per recommendations of Reference [6],

$$
\text { as: } I_{r n}=(1 / 150) C_{R a}+(1 / 100) C_{T h}+(1 / 1500) C_{K}
$$

where in both cases $C_{R a}, C_{T h}$ and $C_{K}$ are the specific activities of ${ }^{226} \mathrm{Ra},{ }^{232} \mathrm{Th}$ and ${ }^{40} \mathrm{~K}$ in Bq. $\mathrm{kg}^{-1}$, respectively.

\section{Results}

The range and mean values of activity concentration, dose rates, Radium Equivalent Activities $\left(R a_{e q}\right)$, Representative Level Index $\left(I_{\gamma r}\right)$ and a comparative study are shown in the Tables (2-4), respectively:

The quoted uncertainties were calculated based on the total uncertainty budget considering $1 \sigma$. A comparative study was performed for the activity concentrations and the corresponding dose rates obtained in the present work with other previous measurements (Table 5).

The mean activity of ${ }^{226} \mathrm{Ra}\left({ }^{238} \mathrm{U}\right){ }^{232} \mathrm{Th}$ and ${ }^{40} \mathrm{~K}$ in fifteen soils samples were found to be $31.39 \pm 1.77,63.34 \pm$ 3.27 and $364.47 \pm 15.32$ Bq. $\mathrm{kg}^{-1}$, dry weight, respectively, which contributes to an average gamma dose of $71.08 \pm$ $3.64 \mathrm{nGy} \cdot \mathrm{h}^{-1}$, in air, at a height of one meter above the

Table 2. The range and average values of the activity concentrations

\begin{tabular}{cccc}
\hline \multirow{2}{*}{$\begin{array}{c}\text { Radio- } \\
\text { nuclides }\end{array}$} & \multicolumn{3}{c}{ Activity Concentrations in Bq.kg-1 } \\
\cline { 2 - 4 } & Minimum & Maximum & Average \\
\hline${ }^{226} \mathrm{Ra}$ & $9.88 \pm 0.86$ & $86.95 \pm 3.47$ & $31.39 \pm 1.77$ \\
${ }^{232} \mathrm{Th}$ & $24.07 \pm 1.69$ & $178.07 \pm 6.57$ & $63.34 \pm 3.27$ \\
${ }^{40} \mathrm{~K}$ & $68.01 \pm 4.80$ & $792.68 \pm 29.80$ & $364.47 \pm 15.32$ \\
${ }^{137} \mathrm{Cs}$ & $\mathrm{ND}$ & $\mathrm{ND}$ & $\mathrm{ND}$ \\
\hline
\end{tabular}

Table 3 . The range and average values of the dose rate

\begin{tabular}{cccc}
\hline \multirow{2}{*}{ Dose Rates } & \multicolumn{3}{c}{ In nGy.h $\mathbf{h}^{\mathbf{1}}$} \\
\cline { 2 - 4 } & Minimum & Maximum & Average \\
\hline External $\left(D_{e x}\right)$ & $26.06 \pm 1.81$ & $159.79 \pm 7.00$ & $71.08 \pm 3.64$ \\
Internal $\left(D_{i n}\right)$ & $31.27 \pm 2.17$ & $191.75 \pm 8.40$ & $85.30 \pm 4.37$ \\
\hline
\end{tabular}

Table 4. The range and average values of the Radium Equiva-

\begin{tabular}{|c|c|c|c|c|c|}
\hline \multirow[t]{2}{*}{ Country } & \multicolumn{3}{|c|}{$\begin{array}{l}\text { Mean Activity } \\
\text { Concentrations } \\
\text { in Bq.kg }\end{array}$} & \multirow{2}{*}{$\begin{array}{c}\begin{array}{c}\text { Mean Dose } \\
\text { Rate in } \\
\text { nGy.h }\end{array} \\
\text { D }\end{array}$} & \multirow[t]{2}{*}{ Reference } \\
\hline & ${ }^{226} \mathrm{Ra}$ & ${ }^{232} \mathrm{Th}$ & ${ }^{40} \mathrm{~K}$ & & \\
\hline $\begin{array}{l}\text { Bangladesh } \\
\text { (Ship yards) }\end{array}$ & 31.39 & 63.34 & 364.47 & 71.08 & $\begin{array}{l}\text { Present } \\
\text { study }\end{array}$ \\
\hline Bangladesh(Dhaka) & 33.00 & 016.00 & 574.00 & 81.0 & [7] \\
\hline India(Kotagiri) & 41.00 & 102.00 & 229.00 & 86.0 & [8] \\
\hline USA (California) & 39.40 & 045.60 & 420.00 & 23.0 & [9] \\
\hline Greece & 49.00 & 024.00 & 760.00 & 42.0 & {$[10]$} \\
\hline Taiwan & 30.00 & 044.00 & 653.00 & 56.6 & [11] \\
\hline World Average & 25.00 & 025.00 & 370.00 & 55.0 & [12] \\
\hline
\end{tabular}
lent Activities $\left(R a_{e q}\right)$ and Representative Level Index $\left(I_{y r}\right)$

\begin{tabular}{cccc}
\hline Index & Minimum & Maximum & Average \\
\hline$R a_{e q}$ & $55.91 \pm 3.89$ & $349.85 \pm 13.33$ & $149.91 \pm 7.62$ \\
$I_{y r}$ & $0.40 \pm 0.03$ & $2.43 \pm 0.09$ & $1.09 \pm 0.05$ \\
\hline
\end{tabular}

Table 5. Comparisons of the activity concentrations of ${ }^{226} \mathrm{Ra}$, ${ }^{232} \mathrm{Th}$ and ${ }^{40} \mathrm{~K}$ and the corresponding dose rates

ground surface of the yards. The activity concentration of the anthropogenic radionuclide ${ }^{137} \mathrm{Cs}$ was below the detection limit. The results of activity concentrations have been used to assess the radium equivalent activities $\left(R a_{e q}\right)$ and the representative level index $\left(I_{\gamma r}\right)$ values in the experimental soil samples. The observed mean value of $R a_{e q}$ and $I_{\gamma r}$ in soil is found to be $149.91 \pm 7.62$ and 1.09 $\pm 0.05 \mathrm{~Bq} \cdot \mathrm{kg}^{-1}$, respectively.

\section{Conclusions}

For the radiation protection, the accumulation of information on natural radiation is of great importance. Therefore the present work may be important to carry out an approximately designed program on environmental radioactivity monitoring-aimed at minimizing population exposure which will ensure a proper working environment in the ship breaking yards and also help to save peoples inside and outside the yards.

Comparison of activity concentrations of different radionuclides and their corresponding dose rates with world wide references revealed that there is no anomaly observed in Chittagong Shipbreaking yard in radiological point of view. However, the created baseline data in the present work will help to assess any radiological contamination due to ship breaking activities in the study area in future. 


\section{Acknowledgement}

The corresponding author A. K. M. Moinul Haque Meaze would like to express his sincere thanks and acknowledge to the Bangladesh University Grants Commission (UGC) for providing fund to carry out this Project in the fiscal year 2008-2009. The corresponding author and Project Director also would like to thanks to the Authority of the University of Chittagong, Bangladesh to select his project for obtaining grants from the UGC. The authors would like to thanks to the authorities of different shipbreaking yards for their excellent cooperation.

\section{REFERENCES}

[1] N. A. Matiullah and A. J. A. H. Khatibeh, "Comparative studies of indoor radon concentration levels in Jordan using CR-39 based bag and cup dosimeter,” Health Physics, Vol. 75, No. 1, pp. 60-62, 1998.

[2] IAEA Technical Report Series, "Measurement of radio-nuclides in food and the environment," No. 295, 1989.

[3] K. A. Kabir, S. M. A. Islam, and M. M. Rahman, "Distribution of radionuclides in surface soil and bottom sediment in the district of Jessore, Bangladesh and evaluation of radiation hazard," Journal of Bangladesh Academy of Sciences, Vol. 33, No. 1, pp. 117-130, 2009.

[4] United Nations Scientific Committee on the Effects of Atomic Radiation Report to the General Assembly, 1998. http://www.unscear.org/unscear/en/publications/1988.html
[5] J. Beretka and P. J. Mathew, "Natural radioactivity of Australian building materials, industrial wastes and byproducts," Health Physics, Vol. 48, No. 1, pp. 87-95, 1985.

[6] Report by NEA Group of Experts, "Nuclear energy agency, exposure to radiation from natural radioactivity in building materials," OECD, 1979.

[7] F. K. Mia, S. Roy, N. Touhiduzzaman, and B. Alan, "Distribution of radionuclides in soil samples in and around Dhaka city,” Applied Radiation and Isotopes, Vol. 49, No. 1-2, pp. 133-137, 1998.

[8] S. Selvasekarapandian, N. M. Manikandan, R. Sivkumar, V. Meenakshinundaram, and V. Raghunath, "Natural radiation distribution of soils at Kotagiri Taluk of the Nilgiris biosphere in India,” Radio-Analytical and Nuclear Chemistry, Vol. 252, No. 2, pp. 429-435, 2002.

[9] J. G. Ingersoll, “A survey of radionuclide contents and radon emanation rates in building materials used in the $U$. S.," Health Physics, Vol. 45, No. 2, pp. 362-368, 1983.

[10] C. Papastefanou, S. Stoulos, M. Manolopoulou, A. Ioannidou, and S. Charalambous, "Indoor radon concentrations in Greek apartment dwellings,” Health Physics, Vol. 66, No. 3, pp. 270-273, 1994.

[11] C. J. Chen, P. S. Weng, and T. C. Chu, "Evaluation of natural radiation in houses built with black schist," Health Physics, Vol. 64, No. 1, pp. 74-78, 1983.

[12] M. Shohag, "Measurement of the natural and artificial radio activity in soil of Mymensingh district of Bangladesh,” M. S. Thesis, University of Chittagong, Bangladesh, 2007. 